\title{
Los detectives salvajes de Roberto Bolaño: fragmentos y pasajes de la realidad latinoamericana
}

\section{The savage detectives of Roberto Bolaño: fragments and passages of the Latin American reality}

\author{
Alexander Barquero-Rodríguez. \\ Maestrando en Estudios Latinoamericanos \\ Universidad Nacional, Costa Rica \\ jose.barquero.rodriguez@est.una.ac.cr
}

Soñábamos con utopía y nos despertamos gritando Roberto Bolaño, "Déjenlo todo nuevamente"1

\begin{abstract}
Resumen
En su obra Los detectives salvajes, Roberto Bolaño nos invita a hacer un recorrido por la historia de terror vivida tras la instauración de una serie de dictaduras y gobiernos totalitarios durante la década de los sesentas y setentas en la región latinoamericana. A través de una serie de hechos históricos ficcionalizados por un movimiento de poetas estridentistas de Latinoamérica, el autor nos deja entrever, como si se tratase de una radiografía regional, toda una serie de escenarios que van desde la represión y el terrorismo de Estado, hasta el exilio, el patriarcado, la búsqueda de una identidad poética latinoamericana, entre otros. El presente artículo busca establecer una relación entre dichos hechos ficcionales y la realidad histórica latinoamericana.
\end{abstract}

1 Epígrafe tomado de Déjenlo todo, nuevamente, reconocido como el Manifiesto infrarrealista escrito por Roberto Bolaño, que es posible acceder mediante el libro Nada utópico nos es ajeno [Manifiestos infrarrealistas] (2013). 
Palabras claves: Real visceralismo, movimientos estridentistas, identidad, poesía latinoamericana, migración, exilio, memoria, dictaduras en el cono sur.

\begin{abstract}
In his novel, The savage detectives, Roberto Bolaño invites us to walkthrough the history of terror experienced after the establishment of a series of dictatorships and totalitarian governments during the sixties and seventies in the Latin American region. Through a series of historical facts fictionalized by a movement of Latin Ameican strident poets, the author lets us glimpse, as if it were a regional radiography, a whole series of scenarios ranging from repression and state terrorism, to the exile, patriarchy, the search for a Latin American poetic identity, among others. This article seeks to establish a relationship between these fictional facts and the Latin American historical reality.
\end{abstract}

Keywords: Real visceralismo, strident movements, identity, Latin American poetry, migration, exile, memory, dictatorships in the south America.

$\mathbf{E}$ 1 presente artículo aborda la novela Los detectives salvajes (1998) del escritor chileno Roberto Bolaño, desde una perspectiva que relaciona los acontecimientos ficcionales ahí resaltados con la historia latinoamericana, de tal forma que se permite visibilizar cómo a través de la obra, el autor da cuenta de distintos sucesos históricos durante la década de los años sesentas y setentas, que fungen como una suerte de radiografía regional de las problemáticas que aquejaban a las sociedades latinoamericanas de la época.

Para comprender el contexto histórico en el que nos sitúa Bolaño, resulta menester primero realizar un acercamiento a este, por lo que debemos de situarnos en un escenario internacional, en el que tras la derrota sufrida por parte de los Estados Unidos de América -EE.UU.- en Vietnam, Latinoamérica fue envestida por una enorme ofensiva direccionada a disipar el creciente avance de las luchas populares de la región, que disentían de las posturas estadounidenses lideradas por Richard M. Nixon. Esto dio pie a afianzar las condiciones para el surgimiento de una ola de autoritarismo en la región, a cargo de las oligarquías tradicionales y los emergentes círculos burgueses asociados al capital transnacional, que contaban además con el beneplácito de los EE.UU.

Dentro de las medidas ejecutadas, cabe destacar la ilegalización de partidos, organizaciones sindicales y estudiantiles, la derogación de constituciones democráticas e, incluso, el cierre de los parlamentos.

[Fue el inicio de una serie de] regímenes de corte fascista, o que aplicaban ciertos métodos fascistas, surgidos en su mayoría de sangrientos golpes militares, [que] se instalaron uno tras otro en diferentes países latinoamericanos, con su secuela de presos, torturados, 
asesinados o desaparecidos, haciendo gala de un absoluto desprecio por los derechos humanos y las libertades democráticas. (Guerra, 2015, p. 475)

En el caso de Suramérica, fue Brasil el país que abrió el portillo a una escalada de gobiernos dictatoriales posteriores, pues para el 31 de marzo de 1964 instauró una dictadura de corte fascista, que se encargó de erradicar del mapa político nacional cualquier muestra de disidencia contra el gobierno, y se convirtió así en el precedente del ascenso del fascismo en América Latina durante la posterior década de los setentas. El fascismo brasileño inspiró los cruentos golpes militares en: Bolivia el 21 de agosto de 1971, la instalación de un gobierno cívico-militar en Uruguay el 27 de junio de 1973, el golpe contrarrevolucionario que derrocó al gobierno democrático de Salvador Allende en Chile el 11 de septiembre del mismo año, o el golpe de Estado en Argentina el 24 de marzo de 1976 perpetrado por el genocida Jorge Rafael Videla.

Asimismo, cabe recalcar la constitución de una vasta operación represiva de carácter continental como lo fue el Plan Cóndor, del cual, en el libro homónimo de João Pina, se destaca que para inicios de los ochentas ya había cobrado la vida de unas 60.000 personas (Pina, 2014). Partiendo, por tanto, de dicha contextualización, cabe destacar que Bolaño, a lo largo de la obra, nos permite entrever cómo a través de la entrada y salida en escena de muchos de los personajes del libro, existe una relación muy fuerte con toda la violencia gestada durante el periodo mencionado en Suramérica y México: los procesos migratorios tales como personas exiliadas políticas huyendo de estas realidades, las desapariciones, el terrorismo de Estado del que no se vio eximido México, los movimientos estudiantiles organizados, la confrontación ideológica, el circulo de intelectualidad del que formaban parte los grupos exiliados suramericanos, entre otros aspectos.

También es posible detectar en la novela la presencia de este tipo de hechos, pero relacionados con la realidad mexicana y que se encuentran rondando en diferentes secciones de la obra, como lo fue la Matanza de Tlatelolco, o la ocupación militar de la ciudad universitaria de la $\mathrm{UNAM}^{2}$. Quizá aparecen y reaparecen en el texto, como lo hacen de la memoria de la nación mexicana, como una herida aún no cicatrizada que de pronto arde. Que arde por centenares de estudiantes que murieron en el año de 1968, el año que los grupos de estudiantes hicieron suyo, el año de las revueltas. Y ello nos acerca al mismo tiempo a mostrarnos un México no muy ajeno ni lejano a Suramérica (Aboites, 2004, p. 285):

El presidente Díaz Ordaz creía ver una conspiración comunista que amenazaba la estabilidad nacional. Conforme se acercaba el inicio de los XIX Juegos Olímpicos, que serían inaugurados en la ciudad de México el 12 de octubre de ese mismo año, la situación se fue complicando. En septiembre el ejército ocupó y desocupó las instalaciones de la UNAM, así como las del IPN ${ }^{3}$. El desenlace llegó en la tarde del 2 de octubre. En una trama que apenas empieza a desentrañarse, los estudiantes reunidos en la plaza de Tlatelolco fueron atacados por

2 UNAM son las siglas de la Universidad Nacional Autónoma Metropolitana de la Ciudad de México.

3 IPN corresponde a las siglas del Instituto Politécnico Nacional de la Ciudad de México. 
soldados del ejército ... Decenas murieron y centenares más fueron recluidos en el penal de Lecumberri ...

El año 1968 fue, además, el año en que Bolaño arribó a México proveniente de Chile. Para ese entonces tenía quince años de edad y pudo mirar cómo los hechos ejecutados por Gustavo Díaz Ordaz le arrebataban la vida a cientos de mexicanos y mexicanas; actos que posteriormente registraría en su novela $\mathrm{Amu}$ leto (1999). Ahora bien, ¿a qué nos referimos con pasajes y fragmentos de la realidad latinoamericana? Nos referimos a esos hechos ficcionalizados por Bolaño en la novela, pero que de alguna u otra forma son un repaso de nuestra historia latinoamericana, son un reflejo fiel de sus realidades. A continuación, se procederá a introducir, de manera muy breve, la obra y acto seguido, abordar cómo el autor hace mención de ello.
Roberto Bolaño fue un escritor y poeta de origen chileno, que en su juventud migró a México en compañía de su familia, específicamente para lo que entonces se conocía como el Distrito Federal. A partir de ese momento se dedicó a la producción de obras literarias y poéticas. Para el año 1976 realiza su primera publicación $\mathrm{y}$, desde entonces, sus cuentos, poemas y novelas alcanzan decenas, sin embargo, su novela Los detectives salvajes es, probablemente, el punto cúspide de su producción. Alcanzó distinciones como el Premio Herral de Novela en España, en 1998, y un año después el Premio Rómulo Gallegos.

La novela consta de tres partes y narra la historia de un colectivo de poetas mayoritariamente de México, así como de otras nacionalidades de la región, que buscaban consagrarse como artistas en

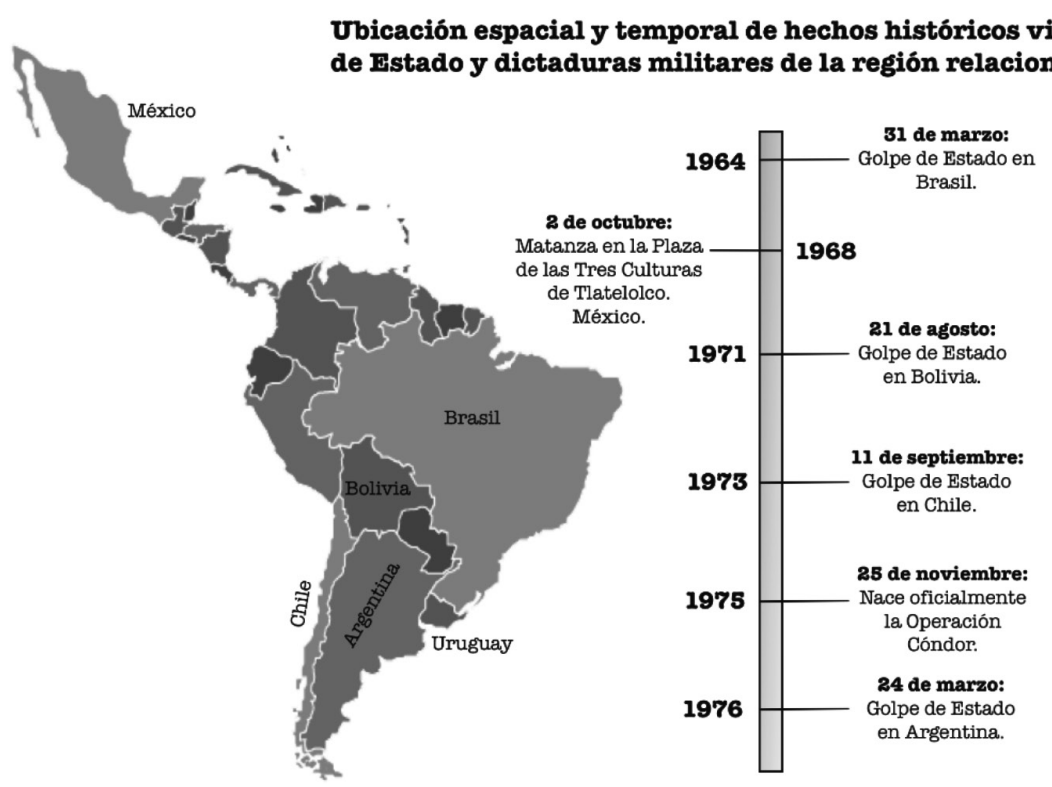

Figura 1. Ubicación espacial y temporal de hechos históricos vinculados al terrorismo de Estado y dictaduras militares de la región relacionados con la obra. Fuente: Elaboración propia del autor del artículo Alex Barquero-Rodríguez. 
contraposición con otras corrientes poéticas de corte más formal y academicista, como la dirigida bajo la tutela de Octavio Paz. El grupo que se rige por lo que llaman "real visceralismo", intenta reivindicar una corriente poética estridentista mexicana de la década de 1920, que fue liderada por Cesárea Tinajero: "Este movimiento [el real visceralismo] supuso un homenaje y un retorno a los vanguardistas de los años veinte, en particular a los estridentistas mexicanos, con quienes compartían una actitud literaria irreverente y desafiante frente a los cánones." (de Mora, 2011, p. 176).

Bolaño nos presenta tres personajes principales: Juan García Madero, quien es estudiante de la Facultad de Derecho de la U.N.A.M. y fue el último miembro en unirse al colectivo. Poco a poco se va desligando de sus estudios universitarios y se va sumergiendo más profundamente en el círculo real visceralista y en la vida bohemia de quienes se encuentran cercanos a él. La primera y última parte del libro son los registros de su diario. Por otra parte, los otros dos personajes de mayor trascendencia en la novela son: el mexicano Ulises Lima y el chileno Arturo Belano, protagonistas de los acontecimientos relatados por García Madero en su diario (Aguilar, 2013, p. 99):

Arturo Belano y Ulises Lima son los líderes del grupo, y parecen dos fantasmas, encarnan la poesía en estado puro, la que no se sustenta con "becas ni espacios en sus revistas ni siquiera invitaciones para ir a presentaciones de libros o recitales". Desde un margen construido a base de imprecaciones e irreverencias estos jóvenes más que escribir poesía la exudan, lectores voraces que buscan la poesía antes de crearla ...

Siguiendo esta línea, el real visceralismo surge tras una investigación realizada por Belano y Lima sobre el estridentismo, en la que uno de los principales hallazgos arrojados fue el descubrimiento de Cesárea Tinajero, una mujer cercana a los grupos estridentistas mexicanos post revolucionarios de los años veinte. Cesárea, considerada como una de las mejores poetas de su época, fundó su propio movimiento, al que bautizó como "real visceralismo", desde el que publicó su primera y única revista denominada: Caborca. Arturo y Ulises, cautivados por el dato, deciden no solo refundar el movimiento en su memoria, sino también iniciar un proceso indagatorio para lograr dar con una pista para encontrar a la poeta.

La primera parte del libro, "Mexicanos perdidos en México (1975)", ofrece una descripción bastante amplia del espacio físico en el cual se desenvuelven los personajes en el Distrito Federal, el estilo de vida que llevan, las relaciones que existen entre ellos, su postura antagonista con respecto al canon academicista de la poesía dominante, así como también se retrata al resto de integrantes del grupo. Respecto al colectivo, se puede decir que pertenecían a una juventud soñadora, idealista y revolucionaria, pero al mismo tiempo, en ocasiones se retrata cómo un aura de cierto pesimismo les embargaba, y no es para más, pues: “... padecen la angustia existencial de una generación que no encuentra las respuestas adecuadas a sus inquietudes" (de Mora, 2011, p. 173). 
La obra recurre a una gran cantidad de espacios para desarrollarse, sin embargo, en la primera parte, el Distrito Federal de México será el escenario predominante por excelencia (de Mora, 2011, p. 174):

Es en esta primera parte donde mejor se proyecta la imagen de la ciudad a través de los itinerarios de la pandilla que practicaba una suerte de nomadismo urbano: en bares, como el «Encrucijada Veracruzana», calle Bucareli, donde solían reunirse; en cafés: el café «Quito», un poco más arriba del Encrucijada, otro punto de encuentro; en las múltiples librerías y, por último, en las zonas y calles. La mayoría de estos lugares adquieren una connotación artística y literaria similar a la que tenía el Café en las vanguardias, al margen de la literatura institucional y en medio de la vida.

La segunda parte de la novela, "Los detectives salvajes (1976-1996)", se desarrolla partiendo del testimonio tanto de miembros del grupo, como de otros poetas, editores, profesores, cercanos al colectivo; estos son Ulises y Arturo, quienes levantan el andamiaje de lo acontecido a lo largo de esas dos décadas. Al mismo tiempo, en esta sección el autor hace gala de todo su vasto conocimiento sobre la literatura latinoamericana, en un gigantesco ejercicio Montaigneano de "sacar los libros de su biblioteca" y exponer minuciosamente los libros destacados que señala a través de sus personajes. Se podría decir, según Aguilar (2013, p. 101):

La novela historiza el recorrido por diferentes concepciones poéticas de América Latina que se remonta a la vanguardia articulada con los procesos de modernización de los años veinte, se detiene en la vanguardia militante de los setenta en el fragor proyectado por la Revolución Cubana y culmina con el cuadro decadente que instala el mercado de los noventa.

En la tercera parte de la obra, "Los desiertos de Sonora (1976)", se da el encuentro esperado con la mesiánica figura de Cesárea Tinajero, transformada en un personaje grotesco y que produce desencanto en quienes fueron a su búsqueda: "Césarea no tenía nada de poética. Parecía una roca o un elefante" (Bolaño, 1998, p. 602). En dicho rastreo, un conjunto de hechos desafortunados lleva al desenlace de la historia y al mismo tiempo esclarece aspectos importantes de la segunda parte.

La utilización de una serie de interrogaciones anexadas en forma de archivos, la recuperación de los testimonios, los datos biográficos, el registro conformado a partir de notas y entrevistas constituyen una búsqueda detectivesca para dar cuenta del núcleo del movimiento vanguardista al cual nunca se accede, pero nos ofrece pistas para un acercamiento al nombre del libro (Corro, 2015, pp. 134-135):

La aplicación del motivo derridiano del "archivo" al capítulo de Los detectives salvajes, resulta sumamente provocadora, puesto que despierta una sensibilidad política de la historia inmediata chilena y latinoamericana, historia catastrófica, que creo no había sido convocada para la lectura crítica de Roberto Bolaño. Los testimonios sobre los poetas desaparecidos, la omisión de la personalidad, circunstancia e intenciones de los narratarios, de los recolectores de relatos, y la falta de fragmentos que contextualicen las informaciones $y$ 
su génesis, todo dispuesto bajo la figura de la acumulación, produce otra imagen sobre la inevitabilidad local de la reconstrucción de una futura comunidad de sentido libre a través de la recuperación indiscriminada e interrogativa de lo ya pasado, de lo ya visto, de lo ya sentido por todos.

El autor chileno hace, por lo tanto, un recorrido no sólo por el sangriento episodio dictatorial latinoamericano, el surgimiento de contingencias populares ante las avasalladoras políticas económicas liberales de la región, movimientos estudiantiles, colectivos estridentistas en contra de los designios formales dominantes dentro del ámbito artístico; sino que también nos remite a una revisión histórica de la tradición literaria latinoamericana (Aguilar, 2013, p. 97):

Bolaño recupera este aspecto de la historia reciente desde diversos espacios que privilegia en tanto se conectan directamente con su biografía. En principio, está Chile y el Golpe de Estado de Augusto Pinochet; luego aparece México con el emblema de Tlatelolco y otros modos de la violencia localizados en el desierto y la frontera (Santa TeresaCiudad Juárez). En segundo lugar, toda su obra dialoga con la tradición literaria latinoamericana armando diferentes cartografias culturales que incluyen desde la poesía chilena y la narrativa argentina a los movimientos más continentales que se nuclean en torno a las vanguardias desde los años veinte, el momento del boom latinoamericano y llega a la literatura reciente en la década de los noventa.

\section{Las heridas del pasado son las cicatrices del presente. Temáticas del libro e interrelación con la historia de América Latina}

El público lector se deberá situar al momento de inicio de la novela en la década de 1970, como lo señala Julia Rial: “ ... a escasos dos años de las luchas estudiantiles del 68 en México, "cuando ardía la infamia de Tlatelolco"; "cuando la juventud se siente decepcionada ante la carencia de nuevas perspectivas sociales y rechaza el silencio gubernamental a sus reclamos." (s. f., p. 5). Sin embargo, a pesar del pesimismo que recaía sobre los hombros de sus protagonistas, ello no fue impedimento para que algunos siguieran su rebeldía idealista hasta las últimas consecuencias, lo que implicó personajes desaparecidos o que terminaron de forma trágica.

Una de las razones por las que quizá pueda aducirse en algunas ocasiones la presencia de pesimismo en los personajes, es la larga y cruenta historia de represión vivida por los protagonistas ya fuera en México o en otras geografías del cono sur (de Mora, 2011, p. 178):

... existe un trasfondo histórico y político de derrota, representado en la novela por el golpe de estado en Chile y la matanza de la plaza de Tlatelolco que ayuda a entender en parte la crisis que viven los personajes y el vacio de sus vidas. Hechos aquellos que no deben considerarse aislados sino como manifestaciones del horror vivido por varios países latinoamericanos en la segunda mitad del siglo XX. Así, aunque aquellos sucesos no constituyan el centro de la novela, la determinan. La escritura de 
Bolaño comparte con la de otros escritores latinoamericanos actuales su naturaleza postdictatorial, la aceptación de la derrota como determinación de la escritura literaria en Latinoamérica.

Roberto Bolaño no se priva de atestiguar una y otra vez, mediante sus personajes, las tragedias que lloró el subcontinente latinoamericano, la sangre inocente derramada, y la cicatriz que aún hoy recuerda el dolor latente de una herida que estuvo ahí. Sobre el asesinato masivo en Tlatelolco recuerda (1998, p. 192):

Y entonces yo llegué al año 1968. O el año 1968 llegó a mí. Yo ahora podría decir que lo presentí, que sentí su olor en los bares, en febrero o en marzo del 68 , pero antes de que el año 68 se convirtiera realmente en el año 68. Ay, me da risa recordarlo. ;Me dan ganas de llorar! ¿Estoy llorando? Yo lo vi todo y al mismo tiempo yo no vi nada. ¿Se entiende? Yo estaba en la facultad cuando el ejército violó la autonomía y entró en el campus a detener o a matar a todo el mundo. No. En la universidad no hubo muchos muertos. Fue en Tlatelolco. ¿Ese nombre que quede en nuestra memoria para siempre!

De igual forma, el texto da cuenta de la naturalización de la violencia dentro del tejido social latinoamericano. Lo anterior implicó que hechos como la Masacre de Tlatelolco fueran asimilados, a pesar de ser una escalada de violencia brutal como la normalidad, incluso llegó a cuestionar los momentos de excesiva tranquilidad. Un ejemplo de cómo calaron profundamente estos hechos sobre el imaginario de uno de los protagonistas, lo ofrece Bolaño justo al inicio de la novela, cuando el personaje narrador de la primera parte, García Madero comenta (1998, p. 15):

... por un momento pensé que tal vez había ocurrido algo en la universidad, una balacera en el campus de la que yo no me hubiera enterado, una huelga sorpresa, el asesinato del decano de la facultad, el secuestro del algún profesor de filosofía o algo por el estilo. Pero nada de esto había sucedido y la verdad era que nadie tenía motivos para estar nervioso. Al menos objetivamente nadie tenía motivos...

Respecto a ello, cabe recalcar cómo toda esta estela de terror previa impacta fuertemente a los personajes miembros del colectivo real visceralista (de Mora, 2011, pp. 178-179):

El mundo de la novela es, por tanto, uno en el que las ilusiones se han derrumbado tanto por los traumas politicos del siglo XX, como por el fracaso de los ideales revolucionarios. Y con ellas también la confianza en el papel de la ficción. Es ese telón de fondo el que ayuda a entender en buena medida la vida sin metas de los personajes: la literatura se convierte para ellos en una tabla de salvación que, sin embargo, no les servirá para mantenerse a flote por mucho tiempo.

En adición, es posible señalar la represión y el terrorismo de Estado en Suramérica, para este caso en específico en Argentina, aunque se hace mención, además, al caso de Chile, país originario de Arturo Belano (Bolaño, 1998, p. 293):

En ese momento cometi un error y le pregunté cómo podía ser tan insensible. Cuando Claudia me miró comprendí 
que la había cagado, pero ya era demasiado tarde. Toda la habitación tembló cuando Claudia se puso a hablar. Dijo que nunca más le volviera a decir eso. Dijo que la próxima vez que lo dijera nuestra relación habría terminado. Dijo que no era una muestra de insensibilidad el no preocuparse en exceso por las aventuras de Ulises Lima. Dijo que su hermano mayor había muerto en Argentina, posiblemente torturado por la policía o el ejército y que eso sí era serio. Dijo que su hermano mayor había luchado en las filas del ERP y que habia creído en la Revolución Americana y eso era muy serio. Dijo que si ella y su familia hubieran estado en Argentina para cuando se desató la represión posiblemente ahora estarían muertos.

De la mano con lo anterior, otra temática que resulta trascendental en el texto, y que de igual manera es una tendencia histórica en América Latina durante el periodo de desarrollo del texto, es la migración. Ello queda evidenciado a primera vista con la presencia de un personaje migrante: Arturo Belano. Se destaca la migración voluntaria en busca de mejores opciones laborales, o bien, la migración forzosa como exilio político, consecuencia de las cruentas represiones acabadas de mencionar (Bolaño, 1998, p. 30):

(...)Pancho Rodríguez habla hasta por los codos. Gracias a él me entero de que antes de la llegada de Belano y Müller (que aparecieron en el D.F. después del Golpe de Pinochet, y por lo tanto son ajenos al grupo primigenio), Ulises Lima había sacado una revista con poemas de María y Angélica Font, de Laura Damián, de Barrios, de San Epifanio, de un tal Marcelo Robles (del que no he oído hablar) y de los hermanos Rodríguez, Pancho y Moctezuma...

Con respecto a la migración, se puede afirmar, además, que no solo se da dentro del continente, sino que también se describen los procesos migratorios fuera de él. En la novela se describe la situación de muchos grupos migrantes latinoamericanos en la ciudad de Barcelona, y se profundiza más que en una simple descripción en sus métodos de sobrevivencia desarrollados, que ilustran las no muy cómodas condiciones en que se vivía (Bolaño, 1998, p. 412.):

A la mañana siguiente sabía que tenía que dejarlo, cuanto antes mejor, y al mediodía llamé a mi madre desde la Telefónica. Por aquellos años ni Arturo ni sus amigos pagaban las llamadas internacionales que solían hacer. Nunca supe qué método utilizaban, sólo supe que era más de uno y que la estafa a Telefónica seguramente fue de miles de millones de pesetas. Llegaban a un teléfono y metían un par de cables y ya estaba, tenían línea, los argentinos eran los mejores, sin duda, y luego venían los chilenos, nunca conocí a un mexicano que supiera como trampear un teléfono, esto tal vez se debe a que nosotros no estamos preparados para el mundo moderno o tal vez a que los pocos mexicanos que por entonces vivían en Barcelona tenían el dinero suficiente como para no necesitar infringir la ley. Los teléfonos tocados eran fácilmente distinguibles por las colas que, sobre todo en las noches, se formaban alrededor de ellos. En esas colas se juntaban lo mejor y lo peor de Latinoamérica, los antiguos militantes y los violadores, los ex presos políticos y los despiadados comerciantes de bisutería. Cuando yo veía esas colas, al volver del cine, en la cabina que había 
en la plaza Ramalleras, por ejemplo, me ponía a temblar, me quedaba helada y un frío metálico como una barra de seguridad me recorría el cuerpo desde la nuca hasta los talones. Adolescentes, mujeres jóvenes con niños de pecho, señoras y señores ya mayores, ¿en qué pensaban, allí, a las doce de la noche o a la una de la mañana, mientras esperaban a que un desconocido terminara de hablar, y cuyo parlamento no podían oír pero sí adivinar, porque el que llamaba solía gesticular o llorar o permanecer largo rato en silencio, sólo afirmando o negando con la cabeza, qué esperaba aquella gente de la cola, que les tocara pronto su turno, que no apareciera la policía? ¿Sólo eso? En cualquier caso, también de ello me aleje. Llamé a mi madre y le pedí dinero.

Por otra parte, el libro aborda un abanico de temáticas bastante amplio, pero quizá una de las principales inquietudes, para el colectivo real visceralista, fue la búsqueda del identitario para poetas de México y Latinoamérica, pues como bien se aprecia, no se traza una diferenciación entre ambas identidades (Bolaño, 1998, p. 150):

Así que nos vimos ese mismo día y cuando llegué al lugar de la cita vi que no era un poeta sino cuatro los que me esperaban y lo que querían no era una entrevista sino un conversatorio, un diálogo a tres bandas para publicar en una de las mejores revistas mexicanas. El diálogo iba a ser entre un mexicano, uno de ellos, un chileno, otro de ellos, y un argentino, yo. Los otros dos que sobraban iban de orejas. El tema: la salud de la nueva poesía latinoamericana. Buen tema. Así que les dije perfecto, cuando quieran empezamos, buscamos una cafetería más o menos tranquila y nos largamos a hablar.
De igual manera, relacionado con el tema de la identidad, Pablo Corro nos ofrece un acercamiento interesante a la intención del colectivo al mismo tiempo de crear comunidad (2015, p. 152): “... la fascinación que produce este libro que se abre como una promesa de que sobre las ruinas de la modernidad es posible la construcción de una comunidad". Es decir, gran cantidad de sus miembros rechazaron formar parte de otros colectivos por un sentimiento de fidelidad hacia el mismo previamente construido; un sentido de pertenencia e identificación al grupo. Además, pretendían que la propuesta que planteaban como movimiento trascendiera las fronteras y se convirtiera en uno latinoamericano (1998, p. 136):

-.. ¿Qué nombre le hubieras puesto tú?
- Ay, no sé. Sección Surrealista Mexi-
cana, tal vez.
- Creo que ya existe una Sección
Surrealista Mexicana en Cuerna-
vaca. Además, lo que nosotros preten-
demos es crear un movimiento a escala
latinoamericana...

Aunado a ello, dentro de este mismo contexto de indagación por el identitario poético, el autor ilustra un contexto latinoamericano de solidaridad durante y post el periodo dictatorial, cuando personas exiliadas políticas son acogidas allende sus fronteras nacionales. Grandes intelectuales y artistas tienen mucha influencia sobre la vida cultural de sus países de acogida, especialmente en México (Bolaño, 1998, p. 150):

... el caso es que en los últimos meses había conocido a poetas jóvenes peruanos, a poetas jóvenes colombianos, a 
poetas jóvenes de Panamá y Costa Rica y no había sentido lo mismo. Yo era un experto en poetas jóvenes y allí ocurría algo raro, faltaba algo, la simpatía, la viril comunión en unos ideales, la franqueza que preside todo acercamiento entre poetas latinoamericanos.

Asimismo, en relación con otras temáticas que han estado presentes a lo largo de la historia latinoamericana, y han golpeado el tejido social de la región, cabe remarcar el patriarcado como una constante histórica. Una situación ilustrativa de esta índole se presentó cuando García Madero le comentó, a la camarera de una cafetería, el peligro que corría Lupe de ser encontrada por Alberto, quien la explotaba como trabajadora sexual, pero a la vez era su pareja (Bolaño, 1998, p. 99):

... Cuando le dije que el tal Alberto podía ser una persona muy peligrosa $\mathrm{y}$ que cabía el riesgo de que, de encontrar a Lupe, la dejara marcada, respondió que una mujer que abandona a su hombre se merecía eso y más.

De igual forma, se detecta la presencia a lo largo de la obra de la masculinidad hegemónica de los protagonistas en razón de distintas situaciones que ilustra el autor. La primera de ellas a destacar se da desde la capacidad de beber alcohol de dos de los protagonistas (Bolaño, 1998, p. 142):

... éntrenle sin desconfianza, y para dar el ejemplo me llené mi vaso y me lo bebí de un solo trago hasta la mitad y luego les serví a ellos y al principio, muchachos del carajo, sólo se humedecieron los labios, pero luego luego les pareció bueno y empezaron a beber como hombres ...
La segunda de ellas se da desde el tamaño del órgano reproductor masculino de otro de los protagonistas, como muestra de su virilidad (Bolaño, 1998, p. 49):

- ¿De qué tamaño la tiene Alberto? Dijo María.

- Del mismo que su cuchillo.

- ¿Y de qué tamaño es su chuchillo? Dijo María.

- Así.

$\ldots$

- ¿Pero tú le has medido la cosita con el cuchillo o hablas sólo a tientas?

- Se lo mide él, no necesito medírselo yo, a mí que más me da, se lo mide él mismo y se lo mide a cada rato, una vez al día, lo menos, dice que para comprobar que no se le ha achicado. ... Dice que es bueno para su hombría.

Otras más también se dan con respecto a esta temática, que deja en evidencia cómo algunos movimientos alternativos al orden hegemónico, como lo es la izquierda latinoamericana, aún no superan el patriarcado como problemática social (Bolaño, 1998, pp. 323-324):

.. y entonces ya no pude aguantarme más y abrí la boca y dije que eso se había terminado, que Rafael sólo hablaba a título personal, como el buen poeta que era, y entonces Rafael me dijo cállate, Barbarita, y yo le dije tú no me callas a mí, mamón, y el cubano dijo ay, las mujeres, e intentó mediar con su mierda de macho con las pelotas podridas y nauseabundas, yo dije mierda, mierda, mierda, sólo queremos publicar en Casa de las Américas a título personal, y el cubano entonces me miró muy serio y dijo que por supuesto, en Casa de las Américas siempre se publicaba 
a título personal, y así les va, dije yo, y Rafael dijo chántala, Barbarita, que el maestro aqui va a pensar lo que no es, y yo dije que el puto maestro piense lo que quiera, pero el pasado es el pasado Rafael, y tu futuro es tu futuro, ¿no?, y entonces el cubano me miró más serio que nunca con unos ojos como diciéndome si estuviéramos en Moscú ibas a acabar tú en un psiquiátrico, chica, ...

Cabe destacar que, así como hubo una gran cantidad gobiernos dictatoriales y represivos, principalmente al sur del continente, también en la pequeña región centroamericana por aquellas épocas surgieron movimientos insurgentes que combatieron fuertemente el despotismo de las elites políticas y económicas de sus países. En la obra, se menciona la revolución sandinista, y uno de los protagonistas se identifica con ella, y hace mención de cómo a más de un miembro del colectivo le hubiera encantado estar ahí (Bolaño, 1998, p. 344):

$Y$ entonces yo le decía: cómo puedes decir que eres marxista, Jacinto, cómo puedes decir que eres poeta si luego haces semejantes declaraciones, ¿Piensas hacer la revolución con refranes? Y Jacinto me contestaba que francamente él ya no pensaba hacer la revolución de ninguna manera, pero que si una noche le diera por allí, pues no sería mala idea, con refranes y boleros, y también me decía que parecía que fuera yo la que se habia perdido en Nicaragua, por lo angustiada que estaba, y quién te dice a ti, decía, que Ulises se perdió en Nicaragua, puede que no se perdiera en absoluto, puede que decidiera quedarse por su propia voluntad, al fin y al cabo Nicaragua debe ser como el sueño que teníamos en 1975, el país donde queríamos vivir.

\section{Reflexión final}

A través de la obra Los detectives salvajes (1998), Roberto Bolaño realiza un recorrido por la historia de terror y genocidio perpetrada por las distintas dictaduras fascistas de la región latinoamericana. Desde los diferentes hechos ficcionalizados por sus personajes nos invita a una reflexión en torno a los sucesos reales acontecidos. Nos adentra desde la metáfora trazada mediante el real visceralismo en un doble sentido: pues al mismo tiempo que se trata de ilustrar la crudeza visceral de la violencia patriarcal; la violencia sufrida por el exiliado político torturado, que dejó atrás muertes a familiares y amistades; las desapariciones; la violencia de la desigualdad socioeconómica; entre otros aspectos, también es una lucha disidente contra lo formal y lo academicista de los círculos intelectuales latinoamericanos.

Es decir, el real visceralismo se convierte en un vehículo dinamizador de la metáfora, una metáfora en la cual se lucha desde la disidencia contra el statu quo hegemónico. Las juventudes latinoamericanas retratadas por Bolaño en su obra, a pesar de estar contagiadas del oscuro pesimismo que nublaba el contexto regional de la época, también se encontraban convocadas por la efervescencia del año 68, la vitalidad de su juventud, sus sueños idealistas, el avance de las luchas populares; y como movimiento estridentista del ámbito artístico poético, estaba llamado, además, a romper con el orden predominante establecido.

Las dictaduras y gobiernos autoritarios de la región durante la década de los setentas, además de controlar el dispositivo 
militar de sus Estados como instrumento represivo, construyeron un fuerte aparato ideológico-cultural de dominación, para erradicar del mapa cualquier intento de regreso hacia un proyecto político y social alternativo. Todo ello fungió como una camisa de fuerza para la sociedad civil afectada. De tal forma que Bolaño plantea un reclamo explícito a la poesía formal y academicista latinoamericana, ante su falta de compromiso político de acuerdo con el contexto social e histórico de la época. Es, por lo cual, una crítica tanto a la imposición dictatorial como a la rigidez del arte.

Asimismo, resulta menester destacar: ¿Desde dónde escribe el autor? Pues el lugar de enunciación de Roberto Bolaño en la novela se encuentra del lado de los sectores perdedores o, por decirlo de otra manera: de los nadies, los grupos olvidados de la historia.

Lo anterior, pues su obra se identifica con los movimientos populares reprimidos, con los estudiantes que masacraron en las revueltas del 68 o las dictaduras suramericanas, con los grupos migrantes desposeídos y solitarios en su nuevo hogar de acogida, solo por mencionar algunos. Y así como se encuentra identificado con ellos, también intenta reivindicar el lugar de artistas estridentes, que por el mismo hecho de asumir su lugar como disidentes y su compromiso político fuera de los cánones artísticos dominantes, se han enviado / se envían al espacio de la exclusión e invisibilización. Las personas miembros del colectivo real visceralista estaban dispuestas a quitarse las cadenas de la formalidad del academicismo poético, y asumir sus obras desde una crítica social que expusiera los sufrimientos de la región, y desde una postura contraria a tanta imposición y autoritarismo.

Dentro de este marco el autor utiliza además el recurso del testimonio, que visto desde esta óptica, funge como un medio a partir del cual se le otorgue la voz a quienes nunca se han escuchado, y que esa escucha se convierta en una vía directa de denuncia. Y precisamente ese testimonio venga a configurarse, además, como un rescate de la memoria histórica, en contraposición con el discurso oficial y dominante que rige al interior de los Estados-nación latinoamericanos. De esta forma, la memoria traumática adquiere una significación de trascendencia en la obra y a partir de revivirla se abre el portillo para no repetirla. Mirar hacia el pasado, tal y como nos invita el libro, significa la posibilidad de reconstruir la memoria.

Y si de reconstruir la memoria se trata, el trabajo de Bolaño adquiere mayor monumentalidad cuando realiza un acercamiento para enhebrar las otras memorias latinoamericanas en su conjunto. Asumir nuestra historia como una historia compartida de luchas y resistencias, de represión, de golpes sangrientos, pero también de una solidaridad transnacional que abrió sus puertas a los grupos perseguidos.

Todo lo anterior sin dejar de lado la ironía a la que en ocasiones alude Bolaño. Ironía como escribir sobre el realismo visceral de una manera tan formal y academicista como esta. ¿Qué diría Bolaño? ¿Qué diría de tantas citas academicistas para pensar su obra desde la historia latinoamericana de los sesentas y setentas? ¿Qué diría de 
tantas reflexiones que se quedan guardadas para la Torre de Marfil $^{4}$ de la universidad? Ulises Lima y Arturo Belano construyeron un real visceralismo desde la calle, lo vieron en el sufrimiento de la gente, en su mirada, en el hambre, en la violencia de la persecución política, en los golpes de la vida. La poesía está en todas partes (1998, p. 15):

... Pero la poesía (la verdadera poesía) es así: se deja presentir, se anuncia en el aire, como los terremotos que según dicen presienten algunos animales, especialmente aptos para tal propósito. (Estos animales son las serpientes, los gusanos, las ratas, y algunos pájaros) ...

4 Por "Torre de Marfil" se entiende el aislamiento de algunos escritores y escritoras y personal investigador universitario, que buscan alcanzar la perfección de sus obras, al muy alto costo de permanecer indiferentes ante la realidad social, política, económica, cultural, solo por destacar algunas; y la subsecuente poca satisfacción de las necesidades prioritarias de los grupos más vulnerables desde los aportes que sus investigaciones realizan.

\section{Referencias}

Aboites, L. (2004). Nueva historia mínima de México.El Colegio de México, México.

Aguilar, P. (2013). Libros de arena, desiertos de horror: La narrativa de Roberto Bolaño (Tesis doctoral). Universidad Nacional de la Plata, Buenos Aires, Argentina.

Bolaño, R. (1998). Los detectives salvajes. Barcelona: Editorial Anagrama.

. (2013). Nada utópico nos es ajeno [Manifiestos infrarrealistas]. Guanajuato, México: Editorial Tsunun.

Anaya, J., Ochoa, G., Harrington, J., Méndez, R., Papasquiaro, M., Bolaño, R., Villoro, J. (2013). Nada utópico nos es ajeno [Manifiestos infrarrealistas]. Guanajuato, México: Editorial Tsunun.

Corro, P. (2015). Reseña. Patricia Espinoza, Los detectives salvajes de Roberto Bolaño: La posibilidad de una comunidad. Revista Catedral Tomada. Revista de crítica literaria latinoamericana, 3, 129-136.

De Mora, C. (2011). En torno a los detectives salvajes de Roberto Bolaño. Revista América Sin Nombre, 16, 171-180.

Guerra, S. (2015). Historia mínima de América Latina. Universidad Nacional Autónoma de México, México.

Pina, J. (2014). Cóndor. El plan secreto de las dictaduras sudamericanas. Barcelona: Editorial Blume.

Rial, J. (s. f.). Los detectives salvajes de Roberto Bolaño: Un obituario a la narrativa del siglo XX. Revista Hispanista, 16, 1-7. Disponible en http://www.hispanista.com.br/revista/artigo141.htm 